BLS 34, No 1 2008. DOI: http://dx.doi.org/10.3765/bls.v34i1.3573

(published by the Berkeley Linguistics Society and the Linguistic Society of America)

\title{
Focus on Embedded Adverbials
}

\author{
RAINER LUDWIG, FABIENNE SALFNER, and MATHIAS SCHENNER \\ Zentrum für Allgemeine Sprachwissenschaft (ZAS) Berlin
}

\section{Introduction}

Focus serves to highlight certain parts of an utterance. It turns out, though, that not just any arbitrary constituent can bear focus. In particular, not all classes of adverbials are suitable for focus. Interestingly, the ability of an adverbial to bear focus is connected to its ability to occur in embedded clauses. This paper aims to identify the cases where adverbials may or may not be focused and/or embedded in German, and sketches a semantically based account of the distribution observed.

We start out with a survey of different types of adverbials in section 2, building mostly on previous work by Frey (2003), Frey and Pittner (1998). Section 3 then examines the possibilities of focusing the different adverbial types in main clauses. It will be necessary to distinguish informational focus from contrastive focus (3.1.) before looking at the actual data (3.2.). We then present a straightforward analysis, following Geurts and van der Sandt (2004), for these cases (3.3.). Finally, section 4 discusses the capability of the adverbial classes to a) appear and b) bear informational/contrastive focus inside embedded clauses (4.1.). The analysis presented in section 3.3 is then extended to the embedded cases (4.2.).

\section{Classes of Adverbials}

Frey (2003) distinguishes the following five types of adverbials, depending on their syntactic base positions: (A1) process-related (e.g. manner adverbials), (A2) event-internal (e.g. local), (A3) event-external (e.g. temporal), (A4) frame adverbials and (A5) sentence adverbials. Additionally, we consider (A6) speech act adverbials, which remain unconsidered in Frey (2003). In Frey and Pittner (1998), a previous version, speech-act adverbials are explicitly excluded and treated as parenthetical expressions. The tree in (1) illustrates the base positions of the various types of adverbials according to Frey (2003). 
Rainer Ludwig, Fabienne Salfner, Mathias Schenner

(1) Base positions of adverbials according to Frey (2003)

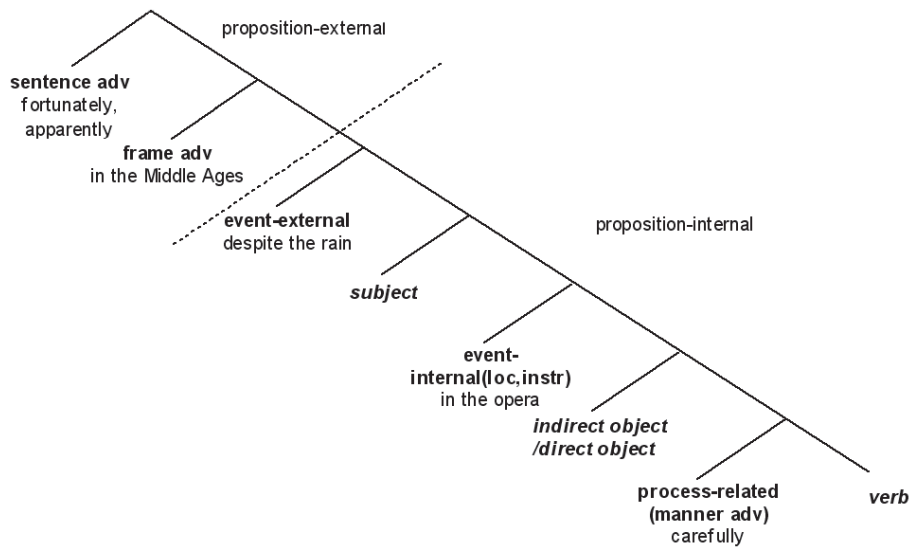

Frey (2003) localizes the process-related adverbials (A1) very close to the verb. The process-related adverbials minimally c-command the base-position of the main predicate.

(2) dass Bea das Buch sorgfältig gelesen hat. that Bea the book diligently read has 'that Bea has read the book diligently'

The base-position of event-internal (e.g. instrumental, locative) adverbials (A2) is minimally c-commanded by the highest ranked argument, usually the subject.

(3) dass Bea mit einem Hammer ein Fenster zerschlagen hat. that Bea with a hammer a window battered has 'that Bea has battered a window by using a hammer.'

Event-external (e.g. temporal) adverbials (A3) c-command the base position of the highest ranked argument.

(4) dass heute niemand abreist. that today nobody leaves

Frame adverbials (A4) c-command the base positions of all arguments and the other adverbials except for the sentence-adverbials.

(5) dass Bea ökologisch betrachtet einen Fehler gemacht hat. that Bea environmentally a mistake made has 'that from an environmental point of view, Bea has made a mistake.' 
Focus on Embedded Adverbials

Sentence adverbials (A5) c-command the base positions of all other adverbials, the finite verb and of all arguments.

(6) dass Bea klugerweise das Buch gelesen hat. that Bea wisely the book read has

According to Frey and Pittner (1998) sentence adverbials relate to propositions, whereas speech-act adverbials relate to utterances. We will see evidence for this conclusion soon, but unlike Frey and Pittner we do not exclude speech-act adverbials (A6) from the discussion for this reason.

(7) dass ehrlich gesagt Bea das Buch gelesen hat that honestly Bea the book read has

In the following sections we will show that the syntactic base position of an adverbial correlates with its ability to bear informational focus or contrastive focus and with its embeddability.

\section{Focus on Adverbials}

\subsection{Informational Focus Versus Contrastive Focus}

É. Kiss (1998) proposes a clear-cut distinction between informational focus (IF) and contrastive focus (CF) (in her terms "identificational focus"). A crucial difference between the two types of foci is that $\mathrm{CF}$ is interpreted exhaustively. This means that when some predicate can possibly hold of some contextually given set of elements, a constituent bearing a CF is marked as the only element or subset of this set for which the predicate actually holds. An IF, on the other hand, merely marks a constituent as non-presupposed. According to É. Kiss, in English a CF is always rendered by a cleft construction, whereas IF can be assigned in situ. The situation is different in German, where the distinction is not always easy to make, since a focused constituent in situ can also express CF. For our concerns however, the crucial question will be whether a given adverbial in a given configuration can bear IF or CF. We will test this as follows: a wh-question is always answered by a sentence with IF.

In order to test whether a given focus in a given sentence can be an IF, we use it as a response to a wh-question asking for the focused constituent, as in (8).

(8) What did Bea batter?

Bea hat $[\text { das FENster }]_{\text {IF }}$ zerschlagen.

Bea has the window battered

On the other hand, a sentence correcting a previous utterance always has CF. In this way, we test whether a given focus can be CF (9): 
Rainer Ludwig, Fabienne Salfner, Mathias Schenner

(9) Bea battered the vase.

Nein, Bea hat [das FENster $]_{\text {CF }}$ zerschlagen.

no Bea has the window battered

The adverbial classes discussed in Section 2 differ with respect to their ability to bear either IF or CF. In the following section, we will present data illustrating this.

\subsection{Data}

As example (10) shows, our classes A1-A3 allow for IF as well as CF.

(10) How closely/where/when did Bea read the book?

Bea hat das Buch [SORGfältig/im GARten/HEUte $]_{\text {IF }}$ gelesen.

Bea has the book diligently/in the garden/today read

'Bea read the book diligently.'

Bea read the book sloppily/in the attic/yesterday.

Nein, Bea hat das Buch [SORGfältig/im GARten/HEUte $]_{\text {CF }}$ gelesen.

no Bea has the book diligently/in the garden/today read

'No, it was diligently that Bea read the book.'

Classes A4 and A5 cannot have IF, but CF is possible:

(11) How did Bea read the book?/What is your opinion of Bea's reading the book?

\# Bea hat [LEIder $]_{\mathrm{IF}}$ das Buch gelesen.

Bea has unfortunately the book read

'Unfortunately, Bea read the book.'

Fortunately, Bea has read the book.

Nein, Bea hat $[\text { LEIder }]_{\mathrm{CF}}$ das Buch gelesen.

no Bea has unfortunately the book Read

'No, it's unfortunately that Bea has read the book.'

(12) How/From what a perspective has Bea committed a crime?

\#[ÖkoLOgisch betrachtet $]_{\mathrm{IF}} \quad$ hat Bea ein Verbrechen begangen. from an environmental perspective has Bea a crime committed 'From an environmental point of view, Bea has committed a crime.'

From an environmental point of view, Bea has committed a crime.

Nein, $[\text { moRALisch }]_{\mathrm{CF}}$ hat Bea ein Verbrechen begangen

no ethically has Bea a crime committed

'No, it's from an ethical perspective that Bea has committed a crime.'

Finally, class A6 may neither bear IF nor CF: 


\section{Focus on Embedded Adverbials}

(13) How has Bea committed a crime?/How serious are you in saying that Bea has committed a crime?

\#[EHRlich gesagt $]_{\mathrm{IF}}$ hat Bea ein Verbrechen begangen.

to be honest has Bea a crime committed

'To be honest, Bea has committed a crime.'

To exaggerate a bit, Bea has committed a crime.

\#Nein, [EHRlich gesagt $]_{\mathrm{CF}}$ hat Bea ein Verbrechen begangen.

no to be honest has Bea a crime committed

'No, it's to be honest that Bea has committed a crime.'

We summarize our results in Table (14):

(14) Focus on Adverbials

\begin{tabular}{|c|c|c|c|}
\hline class & type & IF possible & CF possible \\
\hline A1 & process-related & + & + \\
\hline A2 & event-internal & + & + \\
\hline A3 & event-external & + & + \\
\hline A4 & frame adverbials & - & + \\
\hline A5 & sentence adverbials & - & + \\
\hline A6 & speech act adverbials & - & - \\
\hline
\end{tabular}

\subsection{Analysis}

Focusing divides the content of an utterance into two parts: focus and background. Geurts and van der Sandt (2004) propose the following principle to account for the interpretation of focus:

(15) The Background-Presupposition Rule (BPR)

Whenever focusing gives rise to a background $\lambda x . \varphi(x)$, there is a presupposition to the effect that $\lambda \mathrm{x} . \varphi(\mathrm{x})$ holds of some individual.

For example, (16a) contains a focus feature on 'Barbara', dividing the content of an utterance of the sentence into two parts, focus and background, as indicated in (16b). The background can be thought of as a set of alternatives, and what the BPR does is to introduce a presupposition to the effect that one of these alternatives is true, i.e. for some individual $\mathrm{x}$ it holds that Anna visited $\mathrm{x}$ yesterday.

(16) a. Anna visited [BARbara $]_{\text {IF }}$ yesterday

b. Focus: Barbara

Background: $\lambda \mathrm{x}$. Anna visited $\mathrm{x}$ yesterday

c. Presupposition (via BPR): $\exists x$. Anna visited x yesterday

In the case of contrastive focus (CF), we assume the BPR is operative in the same way, but additionally an exhaustiveness condition is triggered that requires the background to be false of all contextual alternatives to the focus. 
Rainer Ludwig, Fabienne Salfner, Mathias Schenner

(17) a. Anna visited $[\mathrm{BARbara}]_{\mathrm{CF}}$ yesterday

b. Focus: Barbara

Background: $\lambda \mathrm{x}$. Anna visited $\mathrm{x}$ yesterday

c. Presupposition (via BPR): $\exists \mathrm{x}$. Anna visited $\mathrm{x}$ yesterday

d. Exhaustiveness: $\forall \mathrm{x} \in \mathrm{ALT}$ (Barbara) . $\neg$ (Anna visited $\mathrm{x}$ yesterday)

In order to account for the semantic effects of focus on expressions that do not denote individuals, such as adverbials, we assume that the BPR existentially binds every lambda bound variable of a given background, not only individual variables. This is illustrated in (18), where the temporal adverbial heute 'today' is analyzed as a predicate of events.

(18) a. Beahat das Buch $[H E U t e]_{\text {IF }}$ gelesen

Beahas the book today read

Bea read the book today

b. Focus: $\lambda$ e. today(e)

Background: $\quad \lambda \mathrm{P}^{\text {temp }} . \exists \mathrm{e}\left(\right.$ Bea read the book in e and $\left.\mathrm{P}^{\text {temp }}(\mathrm{e})\right)$

c. Presupposition: $\exists \mathrm{P}^{\text {temp }} . \exists \mathrm{e}\left(\right.$ Bea read the book in e and $\left.\mathrm{P}^{\mathrm{temp}}(\mathrm{e})\right)$

In Section 3.2 we have argued that A1-A3 adverbials can bear IF or CF, A4-A5 adverbials can only bear CF and A6 adverbials cannot bear focus at all. The focus facts thus group the six adverbial classes into three categories:

(19) Grouping of Adverbial Classes

\begin{tabular}{|c|c|c|c|}
\hline & $\mathrm{A} 1, \mathrm{~A} 2, \mathrm{~A} 3$ & $\mathrm{~A} 4, \mathrm{~A} 5$ & $\mathrm{~A} 6$ \\
\hline proposition-internal & + & - & - \\
\hline illocutionary & - & - & + \\
\hline focusability & $\mathrm{IF}, \mathrm{CF}$ & *IF, CF & *IF, *CF \\
\hline
\end{tabular}

At this point, two questions arise: (i) Why can't there be any kind of focus on A6 adverbials? (ii) Why can't there be IF on A4-A5 adverbials?

Assuming that focusing divides the content of an utterance in two parts, the answer to (i) is quite straightforward: A6 adverbials do not contribute to the content of an utterance, but operate on the illocutionary level. Since focus cannot operate on this level, A6 adverbials cannot bear any kind of focus.

The second question is harder to answer since the semantic status of A4A5 adverbials is controversial (and probably not homogeneous). Some of them form part of the propositional content, some of them seem to have illocutionary effects (cf. Ifantidou (2001) for English sentence adverbials). For now we assume that they are neither proposition-internal (e.g. they cannot be questioned, in the sense that they cannot be answers to wh-questions) nor illocutionary. In many cases they seem to convey an additional proposition (maybe a conventional implicature) in addition to the main proposition expressed (cf. Potts (2005) for a treatment of higher adverbials along these lines).

So why can't there be IF on A4-A5 adverbials? If an A4-A5 adverbial 


\section{Focus on Embedded Adverbials}

bears IF, the BPR predicts that the complete proposition (below the adverbial) is presupposed, hence there would be nothing left to be asserted. We assume that this rules out IF. However, CF is possible on A4-A5 adverbials, because $\mathrm{CF}$ triggers the assertion of an additional exhaustiveness condition.

The low A1-A3 adverbials pose no special problems: they allow for both IF and $\mathrm{CF}$, since these adverbials are clearly part of the proposition expressed. Both IF and CF on these adverbials can split the propositional content.

\section{Embeddability}

\subsection{Data}

In Section 3.2 we have argued that IF and CF are restricted to certain kinds of adverbials. Now we want to combine these findings with embeddability properties of adverbials. We are confronted with three questions: (i) Which adverbials can occur in embedded contexts? (ii) Which adverbials can bear IF in embedded contexts? (iii) Which adverbials can bear CF in embedded contexts?

If we restrict ourselves to complement clauses as a prototypical case of embedded contexts, we find that A1-A4 adverbials can be embedded under any complement-taking predicate, whereas A6 adverbials cannot be embedded at all. The embeddability of A5 adverbials depends on a combination of factors including the type of embedding predicate and properties of the adverbial itself (cf. Sec. 4.2 for more details). For example, klugerweise 'wisely' can be embedded under glauben 'think' (cf. (20a)), but not under bezweifeln 'doubt' (cf. (20b)).

(20) a. Alex glaubt dass Bea klugerweise das Buch gelesen hat

b. *Alex bezweifelt dass Bea klugerweise das Buch gelesen hat Alex doubts that Bea wisely the book read has

If an adverbial can be embedded, its embedded occurrences can bear IF/CF if and only if its root occurrences can bear IF/CF. For example, embedded occurrences of A1-A3 adverbials can bear both IF and CF (cf. (21)-(23)), whereas embedded occurrences of A4-A5 adverbials can only bear CF focus (cf. (24)(25)).

(21) Alex glaubt dass Bea das Buch [SORGfältig $]_{\mathrm{F}}$ gelesen hat Alex thinks that Bea the book diligently read has

(22) Alex glaubt dass Bea das Bild $[G E R N]_{\mathrm{F}} /[i m H O F]_{\mathrm{F}} /[\text { mit } O \ddot{O}]_{\mathrm{F}}$ gemalt hat Alex thinks that Bea the picture gladly / in the yard/with oil painted has

(23) Alex glaubt dass Bea $[\text { HEUte }]_{\mathrm{F}} /[\text { wegen der HITze }]_{\mathrm{F}}$ abreist Alex thinks that Bea today / due to the heat leaves

(24) Alex glaubt, dass Bea $[\text { moRAlisch }]_{\mathrm{F}}$ ein Verbrechen begangen hat Alex thinks that Bea ethically a crime committed has 
Rainer Ludwig, Fabienne Salfner, Mathias Schenner

(25) Alex glaubt dass Bea $[\text { LEIder }]_{\mathrm{F}}$ das Buch gelesen hat Alex thinks that Bea unfortunately the book read has

A6 adverbials cannot be embedded at all (cf. 26), nor can they bear any kind of focus (cf. Sec. 3.1). The table in (27) summarizes our findings.

(26) * Alex glaubt dass ehrlich gesagt Bea das Buch gelesen hat Alex thinks that honestly Bea the book read has

(27) Focusability and Embeddability of Adverbials

\begin{tabular}{|c|c|c|c|c|c|c|}
\hline class & type & {$[+\mathbf{I F}]$} & {$[+\mathbf{C F}]$} & {$[+\mathbf{e m b}]$} & {$[+\mathbf{I F}+\mathbf{e m b}]$} & {$[+\mathbf{C F}+\mathbf{e m b}]$} \\
\hline A1 & process-related & + & + & + & + & + \\
\hline A2 & event-internal & + & + & + & + & + \\
\hline A3 & event-external & + & + & + & + & + \\
\hline A4 & frame advbs & - & + & + & - & + \\
\hline A5 & sentence advbs & - & + & $(+)$ & - & $(+)$ \\
\hline A6 & speech act advbs & - & - & - & - & - \\
\hline
\end{tabular}

\subsection{Analysis}

Our analysis of focused adverbials in embedded contexts rests on the presupposition theory of focus introduced in Section 3.2. Crucially we assume that the BPR is operative at every CP level, not only at the root level. Embedded occurrences of IF or CF locally trigger a focus presupposition whose fate is determined by independent principles of presupposition projection. More specifically, we adopt the binding theory of presupposition (van der Sandt (1992); Geurts (1999)), framed in (presuppositional) Discourse Representation Theory (DRT). The basic idea is that presuppositions are looking for antecedents in the previous discourse, quite similar to anaphoric elements.

In presuppositional DRT, the interpretation of a sentence involves several steps. First, a so-called "preliminary discourse representation structure (DRS)" is constructed in which all presuppositions of the sentence are represented at their triggering position. Second, the presuppositions are "resolved", which means: if there is an accessible antecedent in the previous discourse, they are bound to it; otherwise they are accommodated as high as possible (without violating certain constraints, e.g. consistency). Third, the resulting final (presupposition-free) DRS is given a model-theoretic interpretation along the usual lines.

At first glance, presuppositions in complements of propositional attitude predicates seem to come in double packages: it can be argued that uttering a sentence like (28a) with the presupposition trigger her cat in the embedded clause gives rise to both presuppositions in (28b). Notice that there is an asymmetry between belief and other attitudes: whatever propositional attitude is chosen as the matrix predicate in (28a), the i-presupposition in (28b) will always be about a belief relation. 


\section{Focus on Embedded Adverbials}

(28) a. Anna believes/hopes/doubts that her cat is sleeping

b. e(xternal)-presupposition: Anna has a cat i(nternal)-presupposition: Anna believes that she has a cat

In the literature, there is no consensus yet regarding the question which of these two presuppositions is more basic. While Karttunen (1974) and Heim (1992) start with the i-presupposition and derive the e-presupposition, we will side with Geurts (1999) in this respect and treat the e-presupposition as more basic. The impression of additional i-presuppositions can then be explained via an independently motivated context-dependent plausibility principle.

Let's see how the analysis works for focus on embedded adverbials, as in (29). Using the BPR (generalized to embedded clauses) we derive (29b) as the preliminary DRS prior to presupposition resolution. The backgrounded material in the complement in (29a) introduces a presuppositional DRS (underlined in (29b)). Since the presupposition cannot be bound in this context, it will be accommodated as high as possible, in this case in the global DRS. The resulting final DRS in (29c) exactly reflects the actual reading of (29a): Bea is leaving and Alex believes that this is happening today.

(29) a. Alex glaubt / bezweifelt dass Bea $[H E U t e]_{F}$ abreist Alex thinks / doubts that Bea today leaves

b. [a: Alex(a), think(a,[b e e: today(e), $\underline{\operatorname{Bea}(b)}, \underline{e}: \operatorname{leave}(b)])]$

c. $[\mathrm{a} b$ e: $\operatorname{Alex}(\mathrm{a}), \operatorname{Bea}(\mathrm{b})$, e:leave(b), think(a,[:today(e)])]

By contrast, in (30) the whole VP Bea heute abreist 'Bea today leaves' is in focus, hence not presupposed, which means that the conditions 'Bea(b)' and 'e:leave(b)' are directly generated in their local DRS without escape potential. The resulting reading is exactly as desired, lacking the presupposition that Bea is leaving.

\section{(30) Alex glaubt / bezweifelt dass [Bea heute ABreist $]_{F}$} Alex thinks / doubts that Bea today leaves

In this example we have been using the A3 adverbial heute 'today', but the mechanism works in exactly the same way for A1 and A2 adverbials, i.e. for all proposition-internal adverbials. A6 adverbials cannot bear any kind of focus, since they exclusively operate at the illocutionary level (cf. Sec. 3.2). Hence we are left with A4 and A5 adverbials which demand special attention. In the following we will concentrate on A5 adverbials, leaving a closer analysis of A4 adverbials for a future occasion.

A5 adverbials form quite a heterogeneous group, comprised of three more basic categories: evaluative (e.g. leider 'unfortunately'), epistemic (e.g. vermutlich 'presumably') and evidential adverbials (e.g. angeblich 'allegedly'). While syntactic evidence suggests a common base position (cf. Frey (2003)), semantically they behave less uniformly. This is reflected in their embeddability properties, summarized in table (31). 
Rainer Ludwig, Fabienne Salfner, Mathias Schenner

(31) Embeddability of Sentence Adverbials

\begin{tabular}{|l|c|c|c|}
\hline & evaluative & epistemic & evidential \\
\cline { 1 - 4 } sagen 'to say' & + & + & + \\
\cline { 1 - 4 } glauben 'to think' & + & + & $-(?)$ \\
\cline { 1 - 4 } wissen 'to know' & + & + & + \\
\cline { 1 - 4 } bezweifeln 'to doubt' & - & + & + \\
\cline { 1 - 4 } bestreiten 'to deny' & - & + & - \\
\hline hoffen 'to hope' & - & - & + \\
\hline
\end{tabular}

Let's consider evaluative adverbials first. Evaluative adverbials can be embedded under utterance and belief predicates, but not under doubt, denial or desire predicates, as illustrated in (32).

(32) Anna sagt / glaubt / weiß / *bezweifelt / *bestreitet / *hofft, dass Bea leider krank ist

'Anna says / thinks / knows / *doubts / *denies / *hopes that Bea unfortunately is sick.'

We take this distribution to follow from the factivity of evaluative adverbials: $\operatorname{leider}(p)$ presupposes that $p$. It is intuitively clear that leider is not a relation between a subject and a proposition, but rather a relation between a subject and a fact (only facts, not propositions themselves, can be unfortunate). Embedded occurrences of leider are both speaker and subject oriented, which renders both (33a) and (33b) infelicitous in usual ("emotionally normal") contexts. The double orientation of leider not only affects its assertive contribution (which may be analyzed as a conventional implicature in the sense of Potts (2005) or as a higher-level explicature in the sense of Ifantidou (2001)), but also its factive presupposition: using leider( $p$ ) in an embedded clause, (i) ascribes to the sentential subject the belief that $p$ and (ii) (at least weakly) commits the speaker to $p$. Hence (34) is infelicitous because the first conjunct contradicts the speaker commitment introduced by embedded leider in the second clause.

(33) a. \#Anna freut sich, dass Bea leider krank ist.

'Anna is glad that Bea is unfortunately sick.'

b. \#Anna bedauert, dass ich leider gesund bin

'Anna regrets that I am unfortunately well.'

(34) \# Ich weiß dass

I know that

Peter kerngesund ist, aber Anna glaubt

dass Peter leider

Peter perfectly.well is but Anna thinks

that Peter unfortunately sick is

Assuming that embedded leider presupposes that the sentential subject takes the embedded proposition to be true, it immediately follows that leider cannot be embedded under doubt or denial predicates, since this would automatically lead to a contradiction. Similarly, the factive character of leider is 


\section{Focus on Embedded Adverbials}

incompatible with future-oriented desire predicates like hoffen 'to hope'.

Epistemic adverbials differ from evaluative ones in various respects. First, they typically contribute to the main proposition expressed. Second, they are not factive. Third, they can occur in complement clauses of a wider range of embedding predicates, including doubt and denial predicates, partly due to the fact that they form part of the embedded proposition.

(35) Anna sagt/glaubt/weiß/bezweifelt/bestreitet dass Bea vermutlich in Berlin ist

'Anna says/thinks/knows/doubts/denies that Bea is probably in Berlin.'

Evidential adverbials like angeblich 'allegedly' show a more complex behavior, because embedded occurrences allow for at least two distinct readings. In complement clauses of wissen 'to know' an assertive reading results (cf. 36a), where angeblich contributes to the truth conditions (similar to 'it is said that'), whereas in complement clauses of bezweifeln 'to doubt' or bestreiten 'to deny' (cf. 36b) a global, seemingly non-truthconditional reading is preferred (similar to the parenthetical 'as it is alleged'). In complement clauses of sagen 'to say' both readings are systematically available. These findings are in line with the readings of other reportative constructions in German (cf. Schenner (2008) on embedded occurrences of the reportative modal sollen 'should').

(36) a. Anna weiß dass Bea angeblich in Berlin ist

'Anna knows that it is said that Bea is in Berlin.'

b. Anna bestreitet dass sie angeblich jemanden umgebracht hat

'Anna denies that she killed someone (as it is alleged).'

To sum up, we have argued that sentence adverbials (A5) do not form a semantically homogeneous class (cf. Ifantidou (2001) for a similar conclusion) and that this explains the variation with respect to their embeddability in clausal complements (e.g. evaluative A5 adverbials, due to their factivity, cannot be embedded under doubt or denial predicates, unlike epistemic and evidential adverbials).

The overall picture is that we have to distinguish three major classes of adverbials with respect to embeddability and focusability. First, A1-A3 adverbials which can bear IF/CF and be embedded. Second, A6 adverbials which can neither bear IF/CF nor be embedded. Third, A4-A5 adverbials which can be embedded (with certain restrictions, see above) and bear CF, but not IF.

\section{References}

É. Kiss, Katalin. 1998. Identificational Focus Versus Information Focus. Language 74(2):245-273. 
Rainer Ludwig, Fabienne Salfner, Mathias Schenner

Frey, Werner and Karin Pittner. 1998. Zur Positionierung der Adverbiale im deutschen Mittelfeld. Linguistische Berichte 176:489-534.

Frey, Werner. 2003. Syntactic conditions on adjunct classes. In E. Lang, C. Maienborn and C. Fabricius-Hansen, eds., Modifying Adjuncts, 163-209. Berlin/New York: de Gruyter.

Geurts, Bart. 1999. Presuppositions and Pronouns. Amsterdam: Elsevier.

Geurts, Bart and Rob van der Sandt. 2004. Interpreting Focus. Theoretical Linguistics, 30(1):1-44.

Heim, Irene. 1992. Presupposition Projection and the Semantics of Attitude Verbs. Journal of Semantics 9:183-221.

Ifantidou, Elly. 2001. Evidentials and Relevance. Amsterdam: Benjamins.

Karttunen, Lauri. 1974. Presuppositions and Linguistic Context. Theoretical Linguistics 1:181-194.

Potts, Chris. 2005. The Logic of Conventional Implicatures. Oxford: Oxford University Press.

van der Sandt, Rob. 1992. Presupposition Projection as Anaphora Resolution. Journal of Semantics 9:333-377.

Schenner, Mathias. 2008. Double face evidentials in German: Reportative 'sollen' and 'wollen' in embedded contexts. In A. Grønn, ed., Proceedings of Sinn und Bedeutung 12, 552-566. Oslo: University of Oslo.

Zentrum für Allgemeine Sprachwissenschaft (ZAS)

Schützenstraße 18

10117 Berlin

Germany

ludwig@zas.gwz-berlin.de

salfner@zas.gwz-berlin.de

schenner@zas.gwz-berlin.de 